\title{
Setup and validation of shake-flask procedures for the determination of partition coefficients $(\log D)$ from low drug amounts
}

\author{
Axel Andrés ${ }^{a}$, Martí Rosés ${ }^{a}$, Clara Ràfols ${ }^{a}$, Elisabeth Bosch ${ }^{a}$, Sonia Espinosa ${ }^{b}$, Víctor \\ Segarrab , Josep M. Huerta \\ ${ }^{a}$ Departament de Química Analítica and Institut de Biomedicina (IBUB), Universitat de Barcelona \\ Martí i Franquès 1-11, 08028 Barcelona (Spain) \\ ${ }^{b}$ Computational and Structural Drug Discovery Department, R\&D Centre, Almirall S.A. \\ Laureà Miró 408-410, 08980 Sant Feliu de Llobregat, Barcelona (Spain)
}

Correspondence to:

Clara Ràfols

Departament de Química Analítica

Universitat de Barcelona

Martí i Franquès 1-11

E-08028 Barcelona (Spain)

Tel: +34934034812

Fax: +34934021233

E-mail: crafols@ub.edu 


\section{ABSTRACT}

Several procedures based on the shake-flask method and designed to require a minimum amount of drug for octanol-water partition coefficient determination have been established and developed. The procedures have been validated by a 28 substance set with a lipophilicity range from -2.0 to $4.5\left(\log D_{7.4}\right)$.

The experimental partition is carried out using aqueous phases buffered with phosphate $(\mathrm{pH} 7.4)$ and $n$-octanol saturated with buffered water and the analysis is performed by liquid chromatography. In order to have accurate results, four procedures and eight different ratios between phase volumes are proposed. Each procedure has been designed and optimized (for partition ratios) for a specific range of drug lipophilicity (low, regular and high lipophilicity) and solubility (high and low aqueous solubility). The procedures have been developed to minimize the measurement in the octanolic phase.

Experimental $\log D_{7.4}$ values obtained from different procedures and partition ratios show a standard deviation lower than 0.3 and there is a nice agreement when these values are compared with the reference literature ones.

\section{SOME CHEMICAL COMPOUNDS STUDIED IN THIS ARTICLE}

Atenolol (PubChem CID: 2249); Salicylic acid (PubChem CID: 338); Metoprolol (PubChem CID: 4171); Caffeine (PubChem CID: 2519); Paracetamol (PubChem CID: 1983); Warfarin (PubChem CID: 54678486); Acetanilide (PubChem CID: 904); Haloperidol (PubChem CID: 3559); Ketoconazole (PubChem CID: 456201); Phenothiazine (PubChem CID: 7108)

\section{KEYWORDS}

Octanol-water partition, hydrophobicity, lipophilicity, $\log D, \log \mathrm{P}_{\mathrm{o} / \mathrm{w}}$, shake-flask technique 


\section{Introduction}

Drug discovery is a relevant step in the development of new drugs. The common procedure is starting with a large number of new potential molecules, test them against biochemical targets and select the ones that show a significant activity, which may be considered as candidates for further development. The next stage in compound selection is identification of those which are more likely to be well absorbed and distributed in the human body and, although a considerable number of routes for absorption of drugs through membranes exist, transport by passive diffusion is the most common one. In order to be absorbed by this route, drugs must be lipophilic enough to penetrate the lipid cores of membranes, but not so lipophilic that they get stuck there (Comer, 2003). So lipophilicity, the measure of affinity of a drug for a lipid environment, has become a parameter of great importance in the pharmaceutical industry because it indicates the relationship of drugs with their biological, pharmacokinetical and metabolic properties (Corwin Hansch and Leo, 1979; Leo et al., 1971; Seydel and Schaper, 1981).

Lipophilicity can be measured by determination of the distribution of a drug between an organic solvent, generally n-octanol saturated with water, and an aqueous phase. The partition coefficient $(P)$ refers to the ratio of compound concentration in each phase and can be determined experimentally by a variety of methods including the well-known shake-flask method (EPA, 1996; OECD 107 Method, 1995), potentiometric methods (Avdeef, 1993, 1992; Ràfols et al., 2012; Takács-Novák and Avdeef, 1996), chromatographic methods (Donovan and Pescatore, 2002; Kaliszan et al., 2002; Liang and Lian, 2015; OECD 117 Method, 2004; Pallicer et al., 2012, 2010; Wiczling et al., 2008) and others. Besides, lipophilicity can also be estimated using computer software and extensive studies about the accuracy of calculated $\log P$ values by different computer software has already been carried out (Chou and Jurs, 1979; Leo, 1987; Mannhold et al., 2009; Pallicer et al., 2014; Tetko et al., 2009). However, when an ionizable compound is equilibrated in a two-phase system at a $\mathrm{pH}$ at which it is partially ionized, its concentration in the organic and aqueous phases is directly related to the distribution coefficient $(D)$, which is defined as the ratio of the concentrations of both the ionized and unionized species of the compound in the organic and aqueous phases at a determined $\mathrm{pH}$ value (Scherrer and Howard, 1977). Both of these 
coefficients, $P$ and $D$, are usually expressed through their logarithms as the most common way to represent lipophilicity. Then, for the general distribution coefficient

$$
\log D=\log \frac{c_{\text {octanol }}}{c_{\text {water }}}
$$

where $c_{\text {octanol }}$ and $c_{\text {water }}$ represent, respectively, the total drug concentration in the phase indicated in the subscript. The $\log D_{7.4}$ of a compound stands for its distribution coefficient at $\mathrm{pH}$ 7.4, and it is considered as a property of utmost importance because of its high physiological relevance and its resemblance to real biological partitions. Besides, it is accepted by most scientists as one of the most relevant lipophilicity descriptors to be applied in absorption, distribution, metabolism, excretion and toxicity (ADMET) studies (Avdeef, 2003; Comer, 2003; Kerns and Di, 2008). The guidelines about log $D_{7.4}$ values and their implication for drug development are illustrated in Table 1 (Comer, 2003; Taylor and Triggle, 2007).

There are many different approaches which can be used to determine a partition coefficient experimentally (Avdeef, 1993; Donovan and Pescatore, 2002; Gulyaeva et al., 2008; Hitzel et al., n.d.; Kaliszan et al., 2002; Pallicer et al., 2012, 2010; Ràfols et al., 2012; Stopher and Mcclean, 1990; Takács-Novák and Avdeef, 1996; Valko et al., 2001; Wiczling et al., 2008), but the most direct one is the shake-flask method. In this method, an aqueous solution of a compound is mixed in a flask with an organic solvent (usually water saturated n-octanol). Then, the flask is shaken to equilibrate the sample between the two phases, and the phases are then separated. Afterwards, the concentration of analyte is measured in both phases. Because of its simplicity and clear relationship to the partitioning phenomenon, the shake-flask is the reference method against other ones when they have to be validated (Comer, 2003).

The well-known shake-flask procedure requires the appropriate selection of the volumes of solvents to employ and the accurate analysis of the solute in both phases. It is also necessary to pay attention to a number of other details if high accuracy is desired, details such as purity of solvents and solutes, solubility of compounds, quickness of the analytical method, formation of micro-emulsions that prevent phases from separating, etc. These and other drawbacks regarding the shake-flask method 
119 have been previously discussed in the literature (Comer, 2003; Dearden and Bresnen, 120 1988; Leo et al., 1971; Purcell et al., 1973; Sangster, 1997; Valkó, 2000).

121 UV spectroscopy and HPLC techniques are most widely used to measure the concentration of the compound in each phase. HPLC offers some advantages such as it requires a smaller amount of compound for the measurement and impurities do not interfere because they are separated from the main component (EPA, 1996; Valkó, 2000). In any case, in order to reduce analysis time, and when no absorption of solute to vessel glass occurs, only one phase should be analyzed and the concentration in the other phase is obtained by difference (Leo et al., 1971). From this point of view, a

where $A_{s t}$ and $A_{w}$ are, respectively, the peak areas of the standard and the aqueous phase of the partition and $V_{w}$ and $V_{o}$ the volumes of water and octanol of the partition. The method proposed was applied to $\log D$ determinations covering a range from -1.5 to 3.5. A limitation of this method is the requirement of a reasonable aqueous solubility of the compound.

Based on the method above, the purpose of this work is to establish systematic experimental procedures able to perform accurate determinations of a wide variety of compounds covering a log $D$ range between -2 and 4.5. Moreover, this study tries to get closer to the needs of the pharmaceutical industries and provide them with simple 
procedures allowing fast routine lipophilicty determination using a very low drug amount and, eventually, using a DMSO solution of the drug instead of its solid form. This is because DMSO solutions of drugs are the usual way to keep the bioactive substances in compound libraries of most pharmaceutical companies.

\section{Fundamentals of the procedures}

Determination of $\log D$ values by the traditional shake-flask method requires the measurement of the compound concentration in octanol and water phases according to Eq. (1), after equilibration of both phases. Thus, Eq. (1) can be written as:

$$
\log D=\log \left(\frac{m_{o}}{m_{w}} \cdot \frac{V_{w}}{V_{o}}\right)=\log \left(\frac{A_{o}}{A_{w}}\right)
$$

where $m$ stands for the mass of compound, $V$ the volume of the phase and the subscripts $w$ and $o$ refer to water and organic phase, respectively.

The most precise measurements are obtained when amounts of drug in both phases are similar. It is evident that this fact depends not only on the particular $\log D$ of the compound, but also on the particular $V_{w} / V_{o}$ ratio used in the shake-flask procedure, because

$$
\log \frac{m_{o}}{m_{w}}=\log D-\log \frac{V_{w}}{V_{o}}
$$

Fig. 1 presents the fraction of compound that remains in water phase after octanol equilibration according to its $\log D$ value and the particular phase ratio used. For $\log D$ values close to 0 , the best results should be obtained when similar volumes of both phases are equilibrated. However, $\log D \ll 0$ would require $\log V_{w} / V_{o} \ll 0$ for precise results, but $\log D \gg>0$ would require $\log V_{w} / V_{o} \gg>0$. Thus, very hydrophilic or very hydrophobic compounds may require very low or very high $V_{w} / V_{o}$ ratios which can be difficult and even impossible to handle. The main objective of this work is to set up appropriate volumes and volume ratio for measuring the $\log D$ of drug of different 
180 lipophilicity, according to the expected lipophilicity, as well as to develop alternative methods for a more practical measurement of $\log D$, especially for drugs with extreme $\log D$ values. The tested volumes and ratios, experimentally feasible, are proposed in Table 2.

The procedure described above requires the HPLC measurement of compound concentration in octanol and water phases. However, HPLC measurement in octanolic phases is very cumbersome. Octanol is a high viscosity solvent (Landolt-Börnstein IV/18B, n.d.) and the injection into a common HPLC column may require a hard and long time consuming cleaning of the column after used. Moreover, its high viscosity determines a low volatility (Sangster, 1997) which makes it an inappropriate solvent for mass spectrometry detection (MS) which is a very common detection technique in physico-chemical parameter determinations and in analytical drug development laboratories.

\subsection{Regular lipophilic compounds (Procedure 1)}

195

For the above reasons, Valkó (Valkó, 2000) proposed the use of the alternative procedure described in the Section 1 involving the measurement of an aqueous standard solution which is later equilibrated with octanol. The $\log D$ value can be calculated from HPLC peak areas of the standard and aqueous phase solutions according to Eq. (1), which can be easily generalized to Eq. (5) if different volumes of the two measured solutions are injected

$$
\log D=\log \left(\left(\frac{A_{s t}}{A_{w}} \cdot \frac{v_{i n j(w)}}{v_{i n j(s t)}} r-1\right) \frac{v_{w}}{V_{o}}\right)
$$

where $v_{i n j(w)}$ and $v_{i n j(s t)}$ are the injection volumes of the aqueous phase of the partition and the standard solution, respectively, and $r$ the adequate dilution factor of the standard solution. Although the application range of Eq. (5) is the same as that of Eq. (3), the procedure avoids measuring octanol phases. The most precise results should 
209 be obtained for phase ratios close to the $D$ values since when $\log V_{w} / V_{o}=\log D$, then

$210 \quad m_{o}=m_{w}=m_{s t}$ for Eq. (4).

211 Of course, the right $V_{w} / V_{o}$ ratio cannot be calculated because the $\log D$ value is not

212 known. However, approximate lipophilicity of the test compound can be usually 213 predicted and an approximate $V_{w} / V_{o}$ value derived. Three shake-flask determinations

214 are proposed: the first partition is done using the $V_{w} / V_{o}$ ratio calculated from the 215 expected $\log D$ value, and the second and third ones with a volume ratio much lower 216 and much higher, respectively. Commonly, at least one of these determinations is 217 precise enough. In principle, the problem of the procedure may come from drugs of 218 very low or very high $\log D$ values which would require very low or very high $V_{w} / V_{o}$ 219 ratios.

\subsection{Poorly lipophilic compounds (Procedure 2)}

For very low $\log D$ values, the lowest feasible $V_{w} / V_{o}$ ratios may not be enough to produce an appreciable partition into the octanolic phase and thus $A_{w} / V_{i n j(w)} \sim$ $A_{s t} \cdot r / V_{\text {inj(st) }}$ and $\log D$ cannot be accurately determined from Eq. (5). In this case, the unique reliable alternative is measuring the octanolic phase, provided that the detector is sensible enough to measure $A_{o}$, and thus calculate $\log D$ according to Eq. (6) which would replace Eq. (5)

$$
\log D=\log \frac{1}{\frac{A_{s t}}{A_{o}} \cdot \frac{v_{i n j(o)}}{v_{i n j(s t)}}-\frac{V_{o}}{V_{w}}} r
$$

\subsection{Highly lipophilic compounds (Procedures $1 b$ and 3)}

For compounds with very high log $D$ values, Eq. (5) can be used if the detector is sensitive enough to determine $A_{w}$ (which will be very small) for the prepared $V_{w} / V_{o}$ ratios. However, in this instance, the problem of highly lipophilic compounds usually arises from their low aqueous solubility. In this case there are several possibilities. In some instances, solubility of the standard solution can be increased by adding a 
cosolvent such as DMSO, currently used to enhance solubility in the drug discovery process (Procedure 1b). Eq. (5) can be used in this case. If the enhancement of the solubility by DMSO is not enough, an alternative procedure is to solve the sample in octanol, instead of water (Procedure 3). To increase the amount of the drug in the aqueous phase, this stock solution is directly equilibrated with the aqueous phase without any dilution. Later, the equilibrated aqueous phase and the stock solution, diluted by an $r$ fator, are measured and $\log D$ can be calculated according Eq. (7)

$$
\log D=\log \left(\frac{A_{s t(o)}}{A_{w}} \cdot \frac{v_{i n j(w)}}{v_{i n j(s t)}} r-\frac{V_{w}}{V_{o}}\right)
$$

These developed procedures (summarized in Fig. 2) shall be tested in this work.

\section{Experimental}

\subsection{Instrumentation}

For HPLC measurements, a Shimadzu HPLC system has been employed; the system consisted of two LC-10ADVP pumps, a SIL-20ACHT auto-injector, a SPD-M10AVP diode array detector (DAD), a CTO-10ASVP oven and a SCL-10AVP controller. The columns used have been a XTerra RP-18 (4.6 x $50 \mathrm{~mm})$ column from Waters (Milford, MA, USA) and a Luna C18 column (4.6 x $50 \mathrm{~mm}$ ) from Phenomenex (Torrance, CA, USA).

For UPLC measurements, a Waters Acquity UPLC system with a Waters Acquity diode array detector has been used. The selected column has been a Waters Acquity UPLC BEH C18 $1.7 \mu \mathrm{m}(2.1 \times 50 \mathrm{~mm})$.

The $\mathrm{pH}$ values of water mobile phases have been measured with a Crison 5014 combined electrode, connected to a GLP 22 potentiometer from Crison (Alella, Spain), with an accuracy of \pm 0.002 in $\mathrm{pH}$ units. The performed partitions have been shaken 
with a rotation shaker movil-ROD from Selecta (Abrera, Spain) in chromatographic vials $(1,5 \mathrm{~mL})$ or, when the partition volume exceeded the vial capacity, in closed test tubes.

\subsection{Chemicals}

Acetonitrile was $99.9 \%$ for HPLC, gradient grade, and has been obtained from Prolabo (West Chester, PA, USA). Double deionized water has been obtained with a Milli-Q system from Millipore (Bedford, MA, USA), with a resistivity of $18.2 \mathrm{M} \Omega \bullet \mathrm{cm}$. Dimethyl sulfoxide from Sigma (St. Louis, MO, USA) and n-octanol from Merck (Darmstadt, Germany) have been also used in this work. A set of 28 compounds from Sigma, covering log $D_{7.4}$ values from -2.0 to 4.5 , has been chosen in order to carry out this study.

\subsection{Procedures}

A phosphate $p H 7.4$ aqueous buffer solution has been prepared and then saturated with n-octanol. Likewise, an n-octanol solution saturated with $p H 7.4$ aqueous buffer has been also prepared. The solubility of octanol in water at room temperature is very low but the one of water in octanol is fairly high (Sangster, 1997), so the saturation of both phases before preparing the partitions is mandatory. Both solutions have been heavily shaken and then left resting for at least 24 hours to ensure complete separation of the two phases. Once the phases have been prepared, the developed procedures, which are summarized in Figure 2, have been tested according to the estimated $\log D$ value and solubility of the compound. $\log D$ estimation can be performed by any of the available software packages, ACDlabs (ACD/Labs, 2012) in this work. Except for Procedure 3, all drugs have been prepared as $10 \mathrm{mM}$ solutions in DMSO, which is taken as stock drug solution.

Procedure 1: The drug solution is diluted in the aqueous $p H 7.4$ phosphate buffer in a 1:100 volume ratio. This solution is taken as standard solution. From it, different partitions are made with different octanol/water ratios according to approximate log $D_{7.4}$ value of the drug. Partitions are shaken for one hour at room temperature. Both 
the standard solution (conveniently diluted, $r$, if necessary) and the aqueous phase of each partition after equilibration are chromatographed for analysis.

Procedure 1b: This procedure is proposed for hydrophobic compounds which form a precipitate when the stock solution is diluted with aqueous phosphate buffer. In that case, the standard solution is prepared by dilution with DMSO ( $r$, usually a dilution with $r=2$ is enough) and chromatographed for analysis. Working partitions are performed in the same way as Procedure 1.

Procedure 2: For hydrophilic compounds, a standard solution is prepared by diluting the drug solution in the $p H 7.4$ phosphate buffer in a 1:40 volume ratio. From the standard solution, the different partitions are made with different octanol/water ratios according to approximate $\log D_{7.4}$ value of the drug. Partitions are shaken for one hour at room temperature. After equilibration, both the standard solution (diluted if necessary) and the octanolic phase of each partition are injected for chromatographic analysis.

Procedure 3: For hydrophobic compounds, the drug is dissolved in n-octanol saturated with aqueous buffer, and then different octanol/water partitions are performed according to the approximate log $D_{7.4}$ value of the drug. The standard solution is prepared by diluting the octanolic solution with water saturated n-octanol (according to the sensitivity of the chromatographic detector). Partitions are shaken for one hour at room temperature. Both the octanolic standard and the aqueous phase, after equilibration of each partition, are chromatographed for analysis.

Whenever possible three different partitions from Table 2 have been chosen for log $D_{7.4}$ determination but in all instances at least two different partitions have been tested. For each partition two or more replicates have been done. Because agitation time is a parameter subject to optimization, the $\log D_{7.4}$ values of some selected compounds have been determined after shaking the partition vials during 1, 2 and 24 hours. No significant differences have been found between the $\log D_{7.4}$ values obtained at different agitation times. Therefore, shaking the partitions for one hour has been 
considered enough agitation time to obtain accurate results in the shortest time possible.

\section{Results and discussion}

\subsection{Test of proposed procedures and water/octanol volume ratios}

14 compounds with $\log D_{7.4}$ values covering a range between -2 and 4.5 units have been selected to test the four procedures described in Section 3.3 (Fig. 2) and the proposed volume ratios (Table 2). Procedures and volume ratios tested for each substance have been chosen according to its predicted hydrophobicity and they are shown in Table 3 as well as the obtained log $D_{7.4}$ values. These predicted values have been obtained through the ACDLabs software (ACD/Labs, 2012) and are only used to give a previous estimation of the lipophilicity which, therefore, allow choosing the proper partitions. The accepted dispersion of results to assure a precision good enough when different experimental conditions are involved in the measurement is \pm 0.3 logarithmic units (EPA, 1996). Then, and if all the partitions and procedures chosen work well, all the log $D_{7.4}$ values obtained for each tested compound should not present a difference greater than 0.3 logarithmic units. Shaded with grey color are those that do not fall within the 0.3 logarithmic units range indicating that these partitions and/or procedures are not suitable for the tested compounds.

It is considered that compounds with intermediate hydrophobicity are those with $\log D$ values between 0 and 2.5. Figure 1 shows that these compounds need volume ratios between log $\left(V_{w} / V_{o}\right)-1.0$ (partition $\mathrm{c}$ ) and 2.7 (partition $\mathrm{h}$ ) to have between $10 \%$ and $90 \%$ of the solute in aqueous and organic phases after equilibration. Then, partitions from $\mathbf{c}$ to $\mathbf{h}$ have been tested with compounds which predicted log $D_{7.4}$ ranges between -0.13 (caffeine) and 2.73 (butyrophenone).

The results obtained (Table 3 ) are in concordance with Fig.1 and show that when log $D_{7.4}$ value increases, partitions with low volume ratio do not provide results good enough and partitions with higher volume ratio must be used. Although Fig. 1 shows that the lowest volume ratio recommended to obtain robust $\log D$ values is the one that implied a $10 \%$ of solute mass in aqueous (or octanolic) phase after equilibration, 
364 in fact this limit depends on the detector used for quantification. When a spectrophotometric detector is used, the lowest limit of any partition depends not only on its sensitivity but also on the absorptivity of the drug. Then, acetanilide, which has a high absorptivity, can be well detected using partition c although only about $1 \%$ of substance remains in aqueous phase after the equilibration step. However, haloperidol, which presents low absorptivity, cannot be well detected when about $10 \%$ of the substance remains in aqueous solution after equilibration, that is, when $\mathbf{f}$ partition is involved in the experimental procedure.

Although partition e with Procedure 1 has been used to determine $\log D_{7.4}$ for caffeine and metoprolol, it is in the lowest $\log D$ limit of applicability. On the other end, partition b with Procedure 2 has also been tested despite it involves a very low aqueous volume, $V_{w}$, difficult to inject properly in the chromatographic system. Thus, Procedure 2, where the octanolic phase is injected, has been applied and Eq. (6) used to calculate $\log D_{7.4}$ values. As shown in Table 3, partition $\mathbf{b}$ with Procedure 2 does not work well with caffeine or metoprolol because less than $5-8 \%$ remain in aqueous phase after equilibration (see Fig. 1), this is a $95-92 \%$ of the drug partition to octanol phase and because $A_{s t} \cdot r / V_{\text {inj(st) }} \sim A_{0} / V_{\text {inj(o), }} \log D$ cannot be accurately determined. Nevertheless the Procedure 2 and partition $\mathbf{b}$ in tandem is suitable for $\log D$ determinations lower than -1 , such as for atenolol or salicylic acid. Although $\log D_{7.4}$ value obtained with this partition is lower than the one predicted for salicylic acid, it is consistent to the one obtained from Procedure 1 and partition c, which are also suitable for this type of compounds, and very close to the one reported in the literature, -1.65 (Biobyte Corp.1995-2006, n.d.). In order to obtain robust $\log D_{7.4}$ values for the most hydrophilic compounds partition c with Procedure 2 has been also performed and no significant differences have been observed with the $\log D_{7.4}$ obtained with the same partition applying Procedure 1.

Because of the low solubility of the most hydrophobic compounds ( $\log D>3.5$ ), Procedure $1 b$ and Procedure 3 have been also tested using partitions $\mathbf{g}$ and $\mathbf{h}$. Table 3 shows the $\log D_{7.4}$ values for phenothiazine and anthracene. For both substances the $\log D_{7.4}$ values obtained from Procedure 1 are lower than the expected ones whereas those from Procedure 3 agree with literature (Biobyte Corp.1995-2006, n.d.). It should be noticed the consistency among values obtained using Procedure $1 b$ (partition $\mathrm{h}$ ) and 
Procedure 3 (partitions $g$ or $h$ ) despite the first one involves a significant amount of DMSO in the standard solutions (see Table 3). Thus, the effect of DMSO on measured $\log D_{7.4}$ seems to be negligible. This assumption is confirmed by results shown in Table 5 for hexanophenone and heptanophenone, compounds not included in Table 3. According to the results given in Table 3, different procedures and volume ratios are proposed for compounds covering a wide range of lipophility, as summarized in Table 4.

\subsection{Precision and Accuracy for the developed procedures}

The recommendations proposed in Table 4 have been applied to determine the $\log D_{7.4}$ value of 28 drugs, including the 14 already analysed, within the log $D_{7.4}$ range between -1.9 and 4.5. Table 5 shows the results obtained when two different systems (HPLC and UPLC both with DAD detector) are used to quantify the solute present in aqueous (or octanolic) phase after equilibration. The obtained results have been compared with the log $D_{7.4}$ values recommended in BioLoom database or when there is no recommended value with the average of the BioLoom values collected at $\mathrm{pH} 7.4$ (Biobyte Corp.1995-2006, n.d.).

At least two different aqueous/octanol volume ratios have been used in all cases and for each ratio three or more determinations have been done. The mean values and their standard deviation shown in Table 5 correspond to the ones computed using all the obtained individual values. When a HPLC-DAD system has been used, the standard deviation for all the compounds is lower than 0.3 log units, in accordance with the EPA guidelines for reliable values (EPA, 1996). Eq. (8) shows the correlation between determined $\log D_{7.4}$ values and the experimental values recommended by the BioLoom database (Biobyte Corp.1995-2006, n.d.).

$$
\begin{gathered}
\log D_{7.4}(\mathrm{HPLC})=0.99( \pm 0.01) \log D_{7.4} \text { (BioLoom) }-0.01( \pm 0.03) \\
n=25 \quad r^{2}=0.99 \quad \mathrm{SD}=0.13 \quad \mathrm{~F}=4716
\end{gathered}
$$

The slope of this correlation is not significantly different from 1 and the intercept from 0 for a $95 \%$ confidence level. Thus, it can be assumed that the methodology applied in 
this work using HPLC-DAD system to quantify the solute provide log $D_{7.4}$ values equivalent to those recommended in the literature with a precision of about 0.15 logarithmic units, given as the standard deviation of the correlation. The correlation is plotted in Fig. 3A.

Fig. 3B and Eq. (9) illustrate equivalence between the $\log D_{7.4}$ values obtained with UPLC and HPLC systems.

$$
\begin{aligned}
& \log D_{7.4}(\mathrm{UPLC})=0.99( \pm 0.02) \log D_{7.4}(\mathrm{HPLC})+0.04( \pm 0.04) \\
& \mathrm{n}=25 \quad \mathrm{r}^{2}=0.99 \quad \mathrm{SD}=0.15 \quad \mathrm{~F}=3200
\end{aligned}
$$

Again, the slope and the intercept obtained in this correlation are not different from 1 and 0 respectively for a $95 \%$ confidence level and thus, no differences in the $\log D_{7.4}$ values are observed when a UPLC system is used instead of HPLC system for quantifying the solute remaining in aqueous (octanolic) phase, as expected. The precision is again of 0.15 logarithmic units. However, the injection of octanol in UPLC cause more overpressures than in HPLC and may produce some troubles in the chromatographic system. Thus, Procedure 2 and Procedure 3, where the octanolic phase is injected, are much less suitable when UPLC system is used. In order to minimize the injection of octanolic phase in this system, partition $\mathbf{b}$ with Procedure 1 has been tested for benzoic acid and, although the partition volume of aqueous phase is small, no difference in $\log D_{7.4}$ value has been obtained with respect to the one from Procedure 2 with HPLC system showing that Procedure 1 can be extended up to a $\log D$ value of about -1.5. Moreover, Procedures 3 (for HPLC) and $1 b$ (for UPLC and HPLC) with the proposed partitions work well for very hydrophobic compounds ( $\log D>3.5$ ). Therefore, Procedure $1 b$ is a good alternative to Procedure 3 and avoids the injection of octanol in the chromatographic system.

Finally, the robustness of Procedures 1 and $1 b$ has been checked selecting a new set of six pharmaceutical compounds in a log $D_{7.4}$ range between 0.5 and 3.8 and their $\log$ $D_{7.4}$ value have been determined by three different analysts. The mean values obtained by these analysts have been compared with the ones obtained by an external company that provides research services to pharmaceutical laboratories (CEREP). Fig. 4 and Eq. (10) show the correlation obtained between the two set of $\log D_{7.4}$ values: 


$$
\mathrm{n}=6 \quad \mathrm{r}^{2}=0.99 \quad \mathrm{SD}=0.09 \quad \mathrm{~F}=591
$$

Because the slope and intercept obtained in this correlation are not significantly different from 1 and 0 respectively (for a 95\% confidence level), it can be concluded that the proposed procedures for routine "in lab" log $D$ determination can substituted the external determination procedures common in many pharmaceutical industries.

\section{Conclusions} (project CTQ2014-56253P) is acknowledged. 


\section{References}

ACD/Labs, 2012. Software, ACD/Percepta Platform v2012.

Avdeef, A., 1992. pH-Metric log P. Part 1. Difference Plots for Determining Ion-Pair Octanol-Water Partition Coefficients of Multiprotic Substances. Quant. Struct. Relationships 11, 510-517. doi:10.1002/qsar.2660110408

Avdeef, A., 1993. pH-metric logP. II: Refinement of partition coefficients and lonization constants of multiprotic substances. J. Pharm. Sci. 82, 183-190. doi:10.1002/jps.2600820214

Avdeef, A., 2003. Absorption and drug development : solutility, permeability, and charge state. Wiley, Hoboken, N.J. :

Biobyte Corp.1995-2006, n.d. BioLoom Online Database [WWW Document]. URL http://www.biobyte.com/bb/prod/bioloom.html

Chou, J.T., Jurs, P.C., 1979. Computer-Assisted Computation of Partition Coefficients from Molecular Structures Using Fragment Constants. J. Chem. Inf. Model. 19, 172-178. doi:10.1021/ci60019a013

Comer, J.E.., 2003. High-throughput Measurement of log D and pKa, Chapter 2, in: Waterbeemd, H. van de, Lennernäs, H., Artursson, P. (Eds.), Drug Bioavailability: Estimation of Solubility, Permeability, Absorption, and Bioavailability. Wiley-VCH, Weinheim.

Corwin Hansch, Leo, A.J., 1979. Substituent Constants for Correlation Analysis in Chemistry and Biology. John Wiley \& Sons Inc.

Dearden, J.C., Bresnen, G.M., 1988. The Measurement of Partition Coefficients. Quant. Struct. Relationships 7, 133-144. doi:10.1002/qsar.19880070304

Donovan, S.F., Pescatore, M.C., 2002. Method for measuring the logarithm of the octanol-water partition coefficient by using short octadecyl-poly(vinyl alcohol) high-performance liquid chromatography columns. J. Chromatogr. A 952, 47-61. doi:10.1016/S0021-9673(02)00064-X

EPA, U., 1996. Product properties test guideline. OPPTS 830.7550 Partition coefficient (n-octanol/H2O), shake flask method [WWW Document]. URL http://www.regulations.gov/\#!documentDetail;D=EPA-HQ-OPPT-2009-0151-0031 (accessed 12.17.14).

Gulyaeva, N., Zaslavsky, a., Lechner, P., Chait, a., Zaslavsky, B., 2008. pH dependence of the relative hydrophobicity and lipophilicity of amino acids and peptides measured by aqueous two-phase and octanol-buffer partitioning. J. Pept. Res. 61, 71-79. doi:10.1034/j.1399-3011.2003.00037.x 
Hitzel, L., Watt, A.P., Locker, K.L., n.d. An increased throughput method for the determination of partition coefficients - ProQuest [WWW Document]. URL http://search.proquest.com/docview/222664289/B2F85C6FD6044B2PQ/8?accou ntid=15293 (accessed 12.16.14).

Kaliszan, R., Haber, P., Bączek, T., Siluk, D., Valko, K., 2002. Lipophilicity and pKa estimates from gradient high-performance liquid chromatography. J. Chromatogr. A 965, 117-127. doi:10.1016/S0021-9673(02)00114-0

Kerns, E.H., Di, L., 2008. Drug-like Properties: Concepts, Structure Design and Methods, Drug-like Properties: Concepts, Structure Design and Methods. Elsevier. doi:10.1016/B978-012369520-8.50026-7

Landolt-Börnstein IV/18B, N.S., n.d. Landolt-Börnstein.

Leo, A., Hansch, C., Elkins, D., 1971. Partition coefficients and their uses. Chem. Rev. 71, 525-616. doi:10.1021/cr60274a001

Leo, A.J., 1987. Some advantages of calculating octanol-water partition coefficients. J. Pharm. Sci. 76, 166-168. doi:10.1002/jps.2600760217

Liang, C., Lian, H., 2015. Recent advances in lipophilicity measurement by reversedphase high-performance liquid chromatography. TrAC Trends Anal. Chem. 68, 2836. doi:10.1016/j.trac.2015.02.009

Mannhold, R., Poda, G.I., Ostermann, C., Tetko, I. V, 2009. Calculation of molecular lipophilicity: State-of-the-art and comparison of log P methods on more than 96,000 compounds. J. Pharm. Sci. 98, 861-93. doi:10.1002/jps.21494

OECD 107 Method, 1995. OECD GUID ELIN E FOR THE TESTIN G OF CHEMICALS Adopted by the Council on 27th July 1995 Partition Coefficient (n-octanol/water): Shake Flask Method [WWW Document]. URL http://www.oecd.org/chemicalsafety/risk-assessment/1948169.pdf

OECD 117 Method, 2004. OECD GUIDELINES FOR THE TESTING OF CHEMICALS. Partition Coefficient (n-octanol/water), High Performance Liquid Chromatography (HPLC) Method [WWW Document]. URL http://www.oecdilibrary.org/docserver/download/9711701e.pdf?expires=1425293587\&id=id\&acc name=guest $\&$ checksum=E0B3F86FA0A5C9C5EE16E7A4CEFF0799

Pallicer, J.M., Calvet, C., Port, A., Rosés, M., Ràfols, C., Bosch, E., 2012. Extension of the liquid chromatography/quantitative structure-property relationship method to assess the lipophilicity of neutral, acidic, basic and amphotheric drugs. J. Chromatogr. A 1240, 113-22. doi:10.1016/j.chroma.2012.03.089

Pallicer, J.M., Pous-Torres, S., Sales, J., Rosés, M., Ràfols, C., Bosch, E., 2010. Determination of the hydrophobicity of organic compounds measured as 
$\log \mathrm{P}(\mathrm{o} / \mathrm{w})$ through a new chromatographic method. J. Chromatogr. A 1217, 302637. doi:10.1016/j.chroma.2010.02.051

Pallicer, J.M., Rosés, M., Ràfols, C., Bosch, E., Pascual, R., Port, A., 2014. Evaluation of $\log \mathrm{Po} / \mathrm{w}$ values of drugs from some molecular structure calculation softwares. ADMET DMPK 2, 107-114. doi:10.5599/admet.2.2.45

Purcell, W.P., Bass, G.E., Clayton, J.E., 1973. Strategy of drug design : a guide to biological activity. Wiley, :

Ràfols, C., Bosch, E., Ruiz, R., Box, K.J., Reis, M., Ventura, C., Santos, S., Araújo, M.E., Martins, F., 2012. Acidity and Hydrophobicity of Several New Potential Antitubercular Drugs: Isoniazid and Benzimidazole Derivatives. J. Chem. Eng. Data 57, 330-338. doi:10.1021/je200827u

Sangster, J., 1997. Octanol-water partition coefficients: fundamentals and physical chemistry. Wiley, Chichester [etc.] :

Scherrer, R.A., Howard, S.M., 1977. Use of distribution coefficients in quantitative structure-activity relations. J. Med. Chem. 20, 53-58. doi:10.1021/jm00211a010

Seydel, J.K., Schaper, K.-J., 1981. Quantitative structure-pharmacokinetic relationships and drug design. Pharmacol. Ther. 15, 131-182. doi:10.1016/01637258(81)90040-1

Stopher, D., Mcclean, S., 1990. An improved method for the determination of distribution coefficients. J. Pharm. Pharmacol. 42, 144-144. doi:10.1111/j.20427158.1990.tb05373.x

Takács-Novák, K., Avdeef, A., 1996. Interlaboratory study of log P determination by shake-flask and potentiometric methods. J. Pharm. Biomed. Anal. 14, 1405-1413. doi:10.1016/0731-7085(96)01773-6

Taylor, J.B., Triggle, D.J., 2007. Comprehensive Medicinal Chemistry II. Elsevier, [S.I.] :

Tetko, I. V, Poda, G.I., Ostermann, C., Mannhold, R., 2009. Large-scale evaluation of log $P$ predictors: local corrections may compensate insufficient accuracy and need of experimentally testing every other compound. Chem. Biodivers. 6, 1837-44. doi:10.1002/cbdv.200900075

Valkó, K., 2000. Separation methods in drug synthesis and purification. Elsevier, Amsterdam :

Valko, K., Du, C., Bevan, C., Reynolds, D., Abraham, M., 2001. Rapid Method for the Estimation of Octanol / Water Partition Coefficient (Log Poct) from Gradient RPHPLC Retention and a Hydrogen Bond Acidity Term (Sigma alpha2H). Curr. Med. Chem. 8, 1137-1146. doi:10.2174/0929867013372643 
Wiczling, P., Waszczuk-Jankowska, M., Markuszewski, M.J., Kaliszan, R., 2008. The application of gradient reversed-phase high-performance liquid chromatography to the $\mathrm{pK}(\mathrm{a})$ and $\log \mathrm{k}(\mathrm{w})$ determination of polyprotic analytes. J. Chromatogr. A 1214, 109-14. doi:10.1016/j.chroma.2008.10.085 


\section{Figure captions}

602

603 Figure 1.- Solute fraction remaining in the aqueous phase for different $\log D$ values 604 after equilibration according to aqueous/organic phases volume ratio. a,b,c,d,e,f,g,and $605 \mathrm{~h}$ partitions defined in Table 2Figure 2.- Flow diagrams of the experimental procedures 606 used in this work.

607 Figure 3.- Comparison of the log $D_{7.4}$ values obtained for the set compounds studied.

608 A) values obtained with the HPLC system vs. values recommended in the BioLoom 609 reference data and B) log $D_{7.4}$ values obtained with the UPLC system vs. the ones 610 obtained with the HPLC system.

611 Figure 4.- Comparison between experimental $\log D_{7.4}$ values with those from an 612 external company. Standard deviation error bars are indicated. 


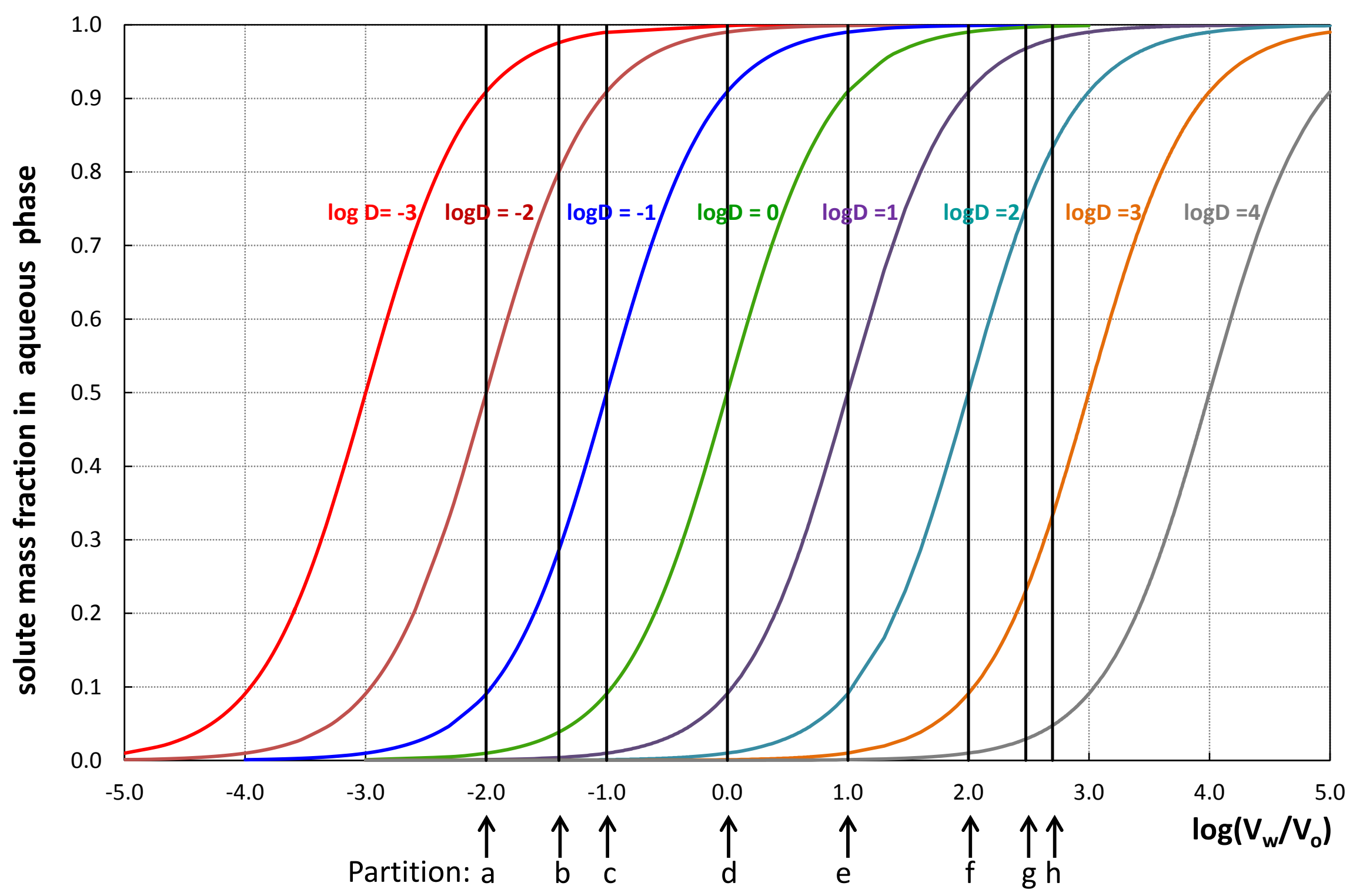




\section{Procedure 1}

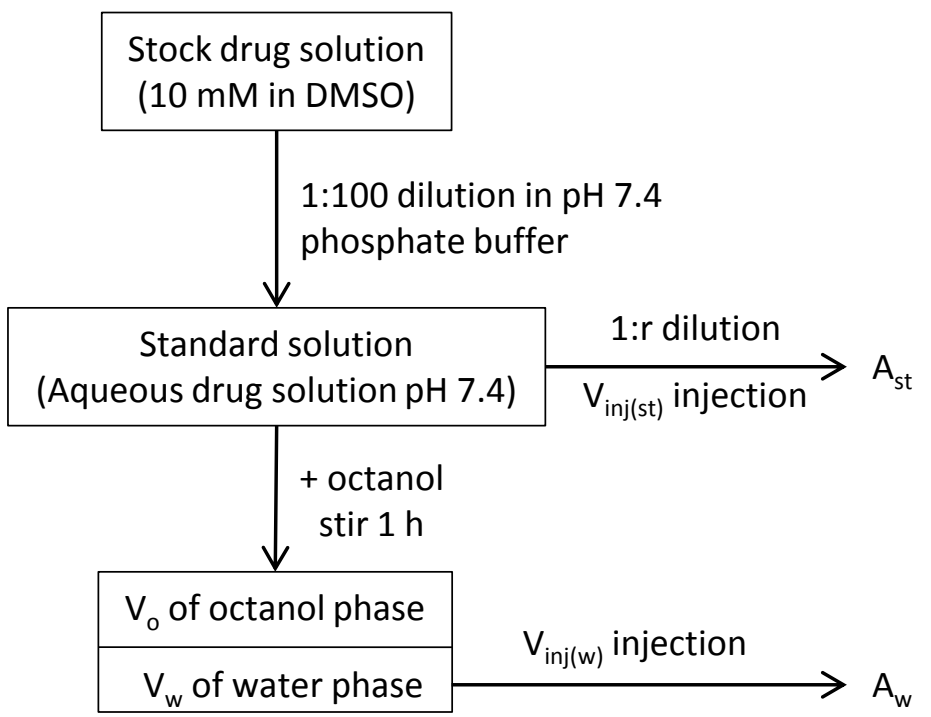

\section{Procedure 2}

Stock drug solution

(10 mM in DMSO)

\section{1:40 dilution in $\mathrm{pH} 7.4$}

phosphate buffer

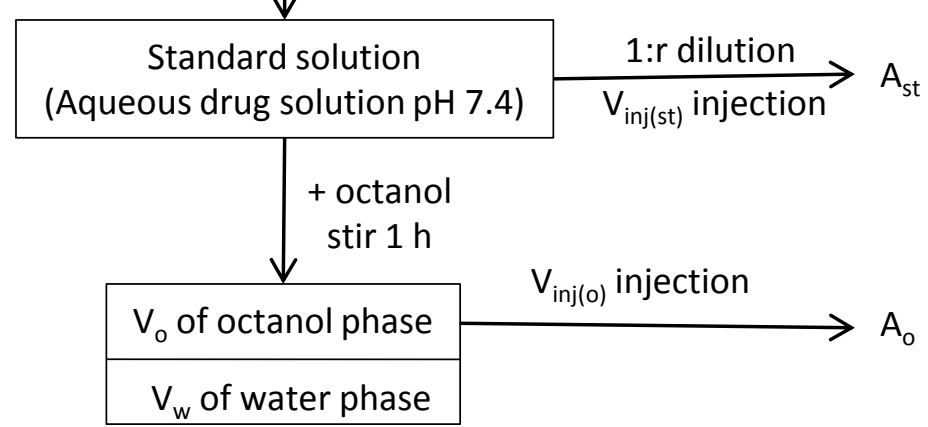

\section{Procedure 1b}

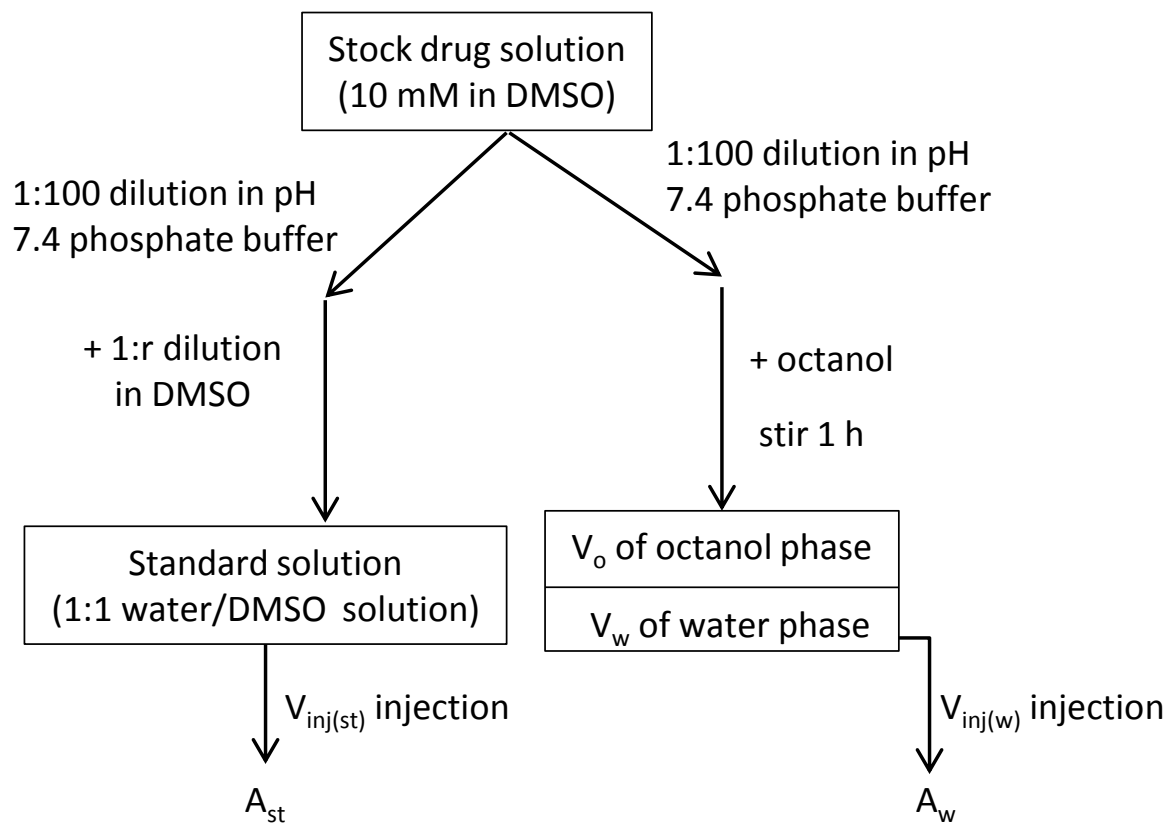

\section{Procedure 3}

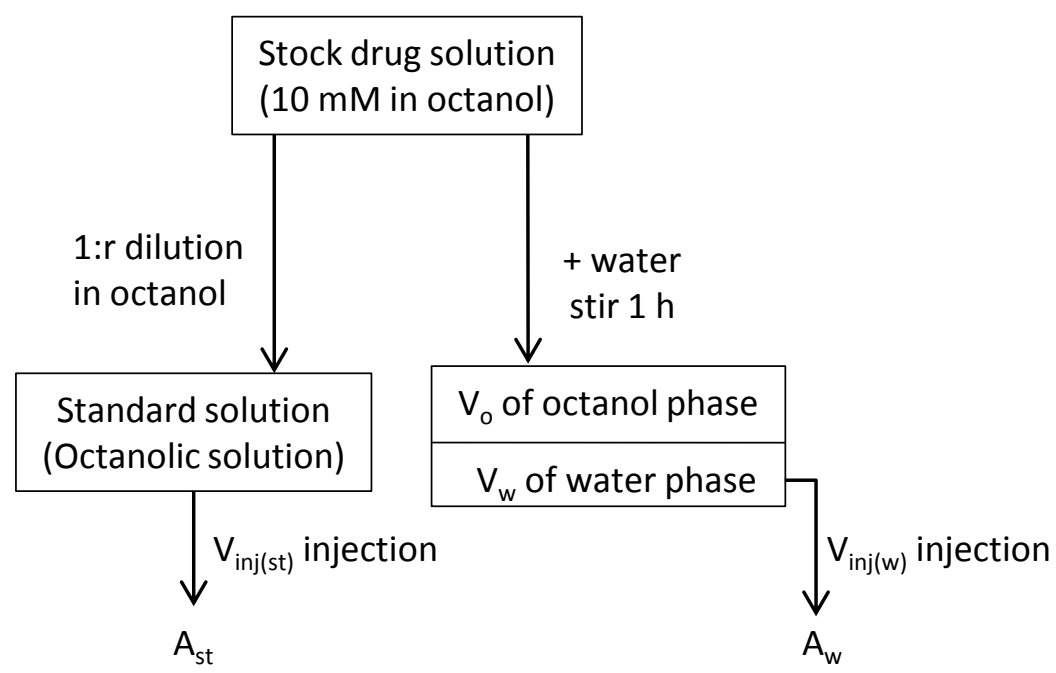



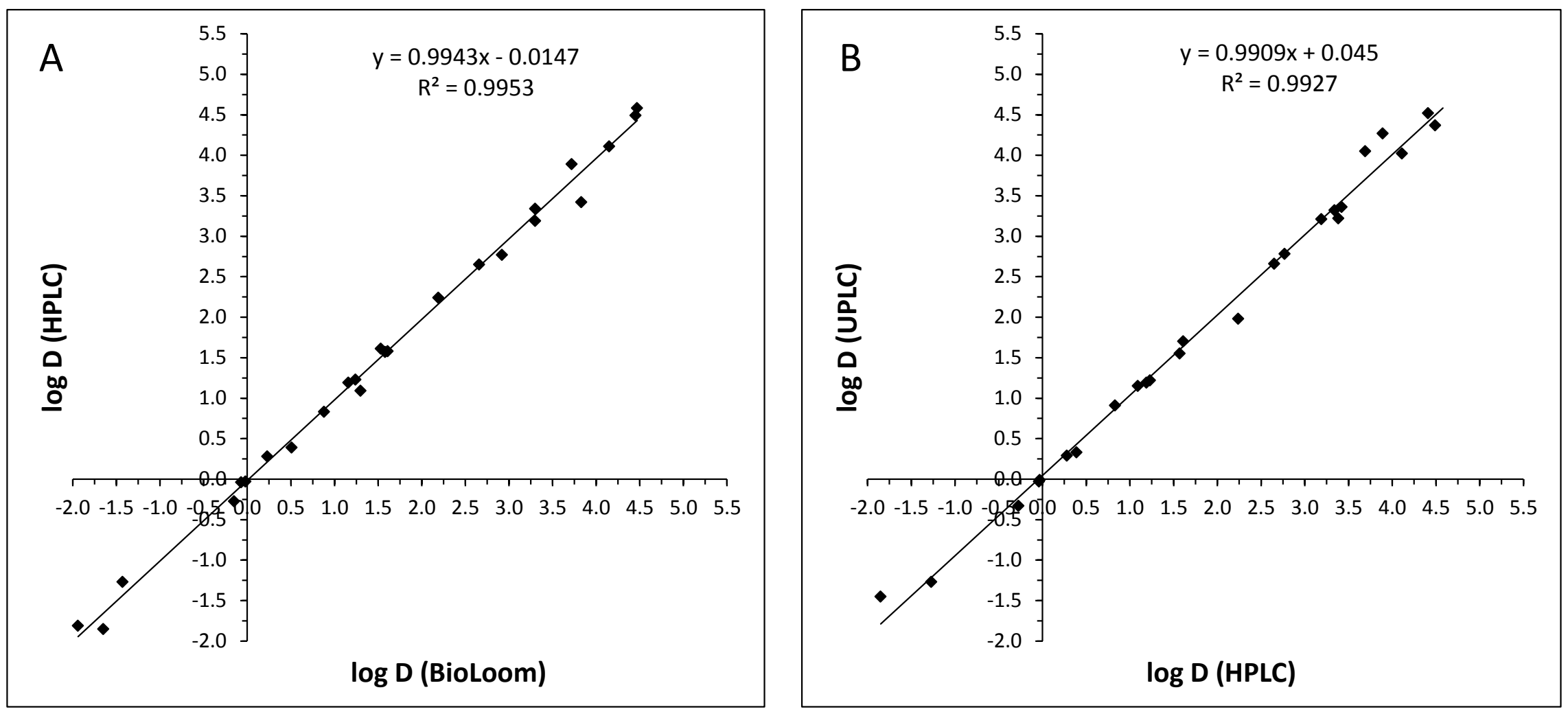


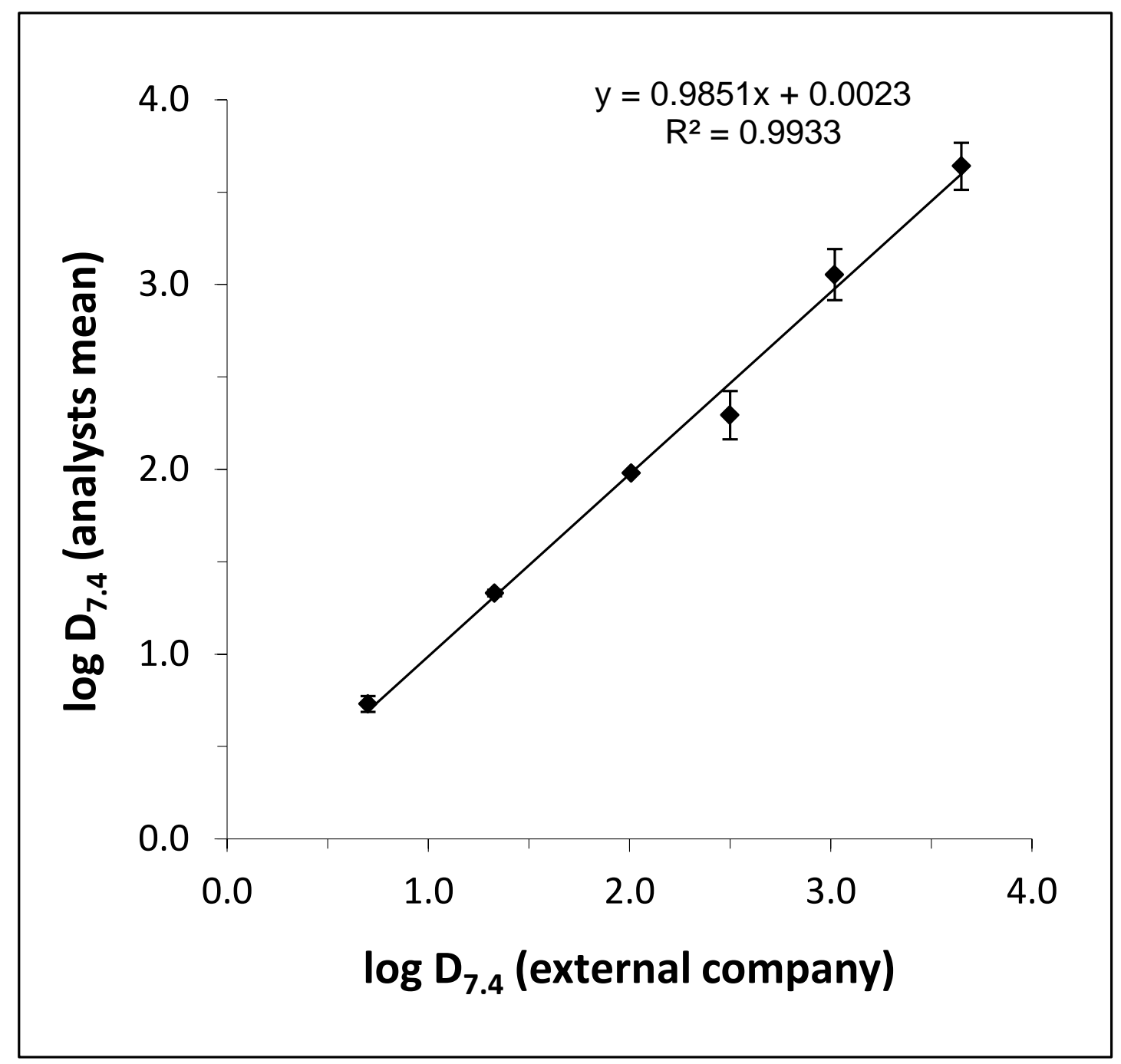


Table 1. Log $D_{7.4}$ values and their implications for drug development (adapted from reference (Comer, 2003; Taylor and Triggle, 2007))

\begin{tabular}{|c|l|}
\hline Log $D_{7.4}$ & Implications for drug development \\
\hline Below 0 & $\begin{array}{l}\text { Intestinal and CNS (central nervous system) permeability problems } \\
\text { Susceptible to renal clearance }\end{array}$ \\
\hline 0 to 1 & May show a good balance between permeability and solubility. \\
\hline 1 to 3 & $\begin{array}{l}\text { Probably an optimum range for CNS and non-CNS orally active drugs. } \\
\text { Generally good CNS penetration. }\end{array}$ \\
\hline 3 to 5 & $\begin{array}{l}\text { Solubility tends to become lower. } \\
\text { Metabolic liabilities tend to increase. }\end{array}$ \\
\hline Above 5 & $\begin{array}{l}\text { Low solubility and poor oral bioavailability. } \\
\text { Erratic absorption. } \\
\text { High metabolic liability, although potency may still be high. }\end{array}$ \\
\hline
\end{tabular}


Table 2: Volume ratios and volumes of aqueous $\left(\mathrm{V}_{\mathrm{w}}\right)$ and octanolic $\left(V_{o}\right)$ phases used for proposed partitions.

\begin{tabular}{ccccc}
\hline Partition & $\mathrm{V}_{\mathrm{w}}(\mathrm{mL})$ & $\mathrm{V}_{\mathrm{o}}(\mathrm{mL})$ & $\mathrm{V}_{\mathrm{w}} / \mathrm{V}_{\mathrm{o}}$ & $\log \mathrm{V}_{\mathrm{w}} / \mathrm{V}_{\mathrm{o}}$ \\
\hline $\mathrm{a}$ & 0.05 & 5 & 0.01 & -2 \\
$\mathrm{~b}$ & 0.2 & 5 & 0.04 & -1.4 \\
$\mathrm{c}$ & 0.5 & 5 & 0.1 & -1 \\
$\mathrm{~d}$ & 0.5 & 0.5 & 1 & 0 \\
$\mathrm{e}$ & 1 & 0.1 & 10 & 1 \\
$\mathrm{f}$ & 1 & 0.01 & 100 & 2 \\
$\mathrm{~g}$ & 3 & 0.01 & 300 & 2.5 \\
$\mathrm{~h}$ & 5 & 0.01 & 500 & 2.7 \\
\hline
\end{tabular}


Table 3: Study of procedures and volume ratios with tested compounds

\begin{tabular}{|c|c|c|c|c|c|c|}
\hline Compound & \begin{tabular}{|c|} 
Predicted ACDLabs $^{\mathrm{a}}$ \\
$\log \mathrm{D}_{7.4}$
\end{tabular} & Procedure & Partition & $v_{w} / v_{o}$ & $\log V_{w} / v_{o}$ & $\begin{array}{c}\text { Measured } \\
\log D_{7.4}\end{array}$ \\
\hline \multirow[t]{5}{*}{ Atenolol } & \multirow{5}{*}{-1.99} & 2 & $a$ & 0.01 & -2 & $-3.01 \pm 0.78$ \\
\hline & & 2 & $\boldsymbol{b}$ & 0.04 & -1.4 & $-1.76 \pm 0.11$ \\
\hline & & 2 & $c$ & 0.1 & -1 & $-1.93 \pm 0.29$ \\
\hline & & 1 & c & 0.1 & -1 & $-1.64 \pm 0.07$ \\
\hline & & 1 & $d$ & 1 & 0 & $-0.58 \pm 0.43$ \\
\hline \multirow[t]{6}{*}{ Salicylic acid } & \multirow{6}{*}{-1.09} & 2 & $a$ & 0.01 & -2 & $-2.31 \pm 0.05$ \\
\hline & & 2 & $\boldsymbol{b}$ & 0.04 & -1.4 & $-1.77 \pm 0.04$ \\
\hline & & 2 & $c$ & 0.1 & -1 & $-1.98 \pm 0.12$ \\
\hline & & 1 & $c$ & 0.1 & -1 & $-1.78 \pm 0.10$ \\
\hline & & 1 & $d$ & 1 & 0 & $-1.35 \pm 0.31$ \\
\hline & & 1 & $e$ & 10 & 1 & $-0.41 \pm 0.08$ \\
\hline \multirow[t]{5}{*}{ Metoprolol } & \multirow{5}{*}{-0.31} & 2 & $b$ & 0.04 & -1.4 & $-0.74 \pm 0.03$ \\
\hline & & 1 & $c$ & 0.1 & -1 & $-0.20 \pm 0.10$ \\
\hline & & 1 & $d$ & 1 & 0 & $-0.35 \pm 0.05$ \\
\hline & & 1 & $e$ & 10 & 1 & -0.33 \\
\hline & & 1 & $f$ & 100 & 2 & $--^{b}$ \\
\hline \multirow[t]{5}{*}{ Caffeine } & \multirow{5}{*}{-0.13} & 2 & $b$ & 0.04 & -1.4 & $-0.40 \pm 0.04$ \\
\hline & & 1 & $c$ & 0.1 & -1 & $-0.08 \pm 0.01$ \\
\hline & & 1 & $d$ & 1 & 0 & $0.00 \pm 0.15$ \\
\hline & & 1 & $e$ & 10 & 1 & -0.13 \\
\hline & & 1 & $f$ & 100 & 2 & $--^{b}$ \\
\hline \multirow[t]{5}{*}{ Paracetamol } & \multirow{5}{*}{0.34} & 2 & $b$ & 0.04 & -1.4 & $1.07 \pm 0.01$ \\
\hline & & 1 & $c$ & 0.1 & -1 & $0.25 \pm 0.01$ \\
\hline & & 1 & $d$ & 1 & 0 & $0.42 \pm 0.03$ \\
\hline & & 1 & $e$ & 10 & 1 & $0.53 \pm 0.20$ \\
\hline & & 1 & $f$ & 100 & 2 & $1.55 \pm 0.17$ \\
\hline \multirow[t]{4}{*}{ Warfarin } & \multirow{4}{*}{0.62} & 1 & c & 0.1 & -1 & $0.74 \pm 0.21$ \\
\hline & & 1 & $d$ & 1 & 0 & $0.83 \pm 0.21$ \\
\hline & & 1 & $e$ & 10 & 1 & $0.86 \pm 0.18$ \\
\hline & & 1 & $f$ & 100 & 2 & $1.04 \pm 0.09$ \\
\hline \multirow[t]{4}{*}{ Acetanilide } & \multirow{4}{*}{1.08} & 1 & c & 0.1 & -1 & $1.15 \pm 0.01$ \\
\hline & & 1 & $d$ & 1 & 0 & $1.21 \pm 0.01$ \\
\hline & & 1 & $e$ & 10 & 1 & $1.20 \pm 0.01$ \\
\hline & & 1 & $f$ & 100 & 2 & $1.17 \pm 0.09$ \\
\hline \multirow[t]{5}{*}{ Acetophenone } & \multirow{5}{*}{1.66} & 1 & $d$ & 1 & 0 & $1.58 \pm 0.13$ \\
\hline & & 1 & $e$ & 10 & 1 & $1.58 \pm 0.30$ \\
\hline & & 1 & $f$ & 100 & 2 & $1.54 \pm 0.11$ \\
\hline & & 1 & $g$ & 300 & 2.5 & $1.61 \pm 0.29$ \\
\hline & & 1 & $\boldsymbol{h}$ & 500 & 2.7 & $1.52 \pm 0.21$ \\
\hline \multirow[t]{3}{*}{ Haloperidol } & \multirow{3}{*}{2.18} & 1 & $d$ & 1 & 0 & $1.66 \pm 0.05$ \\
\hline & & 1 & $e$ & 10 & 1 & $2.04 \pm 0.26$ \\
\hline & & 1 & $f$ & 100 & 2 & $2.53 \pm 0.06$ \\
\hline
\end{tabular}




\begin{tabular}{|c|c|c|c|c|c|c|}
\hline & & 1 & $g$ & 300 & 2.5 & $2.94 \pm 0.12$ \\
\hline & & 1 & $h$ & 500 & 2.7 & $3.08 \pm 0.09$ \\
\hline \multirow[t]{5}{*}{ Butyrophenone } & \multirow{5}{*}{2.73} & 1 & $d$ & 1 & 0 & $2.37 \pm 0.06$ \\
\hline & & 1 & $e$ & 10 & 1 & $2.46 \pm 0.02$ \\
\hline & & 1 & $f$ & 100 & 2 & $2.73 \pm 0.31$ \\
\hline & & 1 & $g$ & 300 & 2.5 & $2.68 \pm 0.16$ \\
\hline & & 1 & $\boldsymbol{h}$ & 500 & 2.7 & $2.83 \pm 0.16$ \\
\hline \multirow[t]{5}{*}{ Valerophenone } & \multirow{5}{*}{3.26} & 1 & $d$ & 1 & 0 & $2.16 \pm 0.14$ \\
\hline & & 1 & $e$ & 10 & 1 & $2.86 \pm 0.02$ \\
\hline & & 1 & $f$ & 100 & 2 & $3.30 \pm 0.15$ \\
\hline & & 1 & $g$ & 300 & 2.5 & $3.38 \pm 0.17$ \\
\hline & & 1 & $\boldsymbol{h}$ & 500 & 2.7 & $3.47 \pm 3.28$ \\
\hline \multirow[t]{3}{*}{ Ketoconazole } & \multirow{3}{*}{3.43} & 1 & $f$ & 100 & 2 & $2.02 \pm 0.53$ \\
\hline & & 1 & $g$ & 300 & 2.5 & $3.50 \pm 0.16$ \\
\hline & & 1 & $\boldsymbol{h}$ & 500 & 2.7 & $3.32 \pm 0.21$ \\
\hline \multirow[t]{6}{*}{ Phenothiazine } & \multirow{6}{*}{4.15} & 1 & $g$ & 300 & 2.5 & $3.86 \pm 0.43$ \\
\hline & & $1 b$ & $g$ & 300 & 2.5 & $3.85 \pm 0.13$ \\
\hline & & 3 & $g$ & 300 & 2.5 & $4.21 \pm 0.18$ \\
\hline & & 1 & $h$ & 500 & 2.7 & $3.84 \pm 0.15$ \\
\hline & & $1 b$ & $\boldsymbol{h}$ & 500 & 2.7 & $4.05 \pm 0.01$ \\
\hline & & 3 & $\boldsymbol{h}$ & 500 & 2.5 & $4.01 \pm 0.24$ \\
\hline \multirow[t]{6}{*}{ Anthracene } & \multirow{6}{*}{4.68} & 1 & $g$ & 300 & 2.5 & $3.47 \pm 0.68$ \\
\hline & & $1 b$ & $g$ & 300 & 2.5 & $3.99 \pm 0.06$ \\
\hline & & 3 & $g$ & 300 & 2.5 & $4.52 \pm 0.21$ \\
\hline & & 1 & $\boldsymbol{h}$ & 500 & 2.7 & $3.83 \pm 0.50$ \\
\hline & & $1 b$ & $\boldsymbol{h}$ & 500 & 2.5 & $4.24 \pm 0.15$ \\
\hline & & 3 & $\boldsymbol{h}$ & 500 & 2.7 & $4.60 \pm 0.11$ \\
\hline
\end{tabular}

${ }^{a}$ from reference (ACD/Labs, 2012). ${ }^{b}$ cannot be determined

Shaded values are those that do not fall within 0.3 logarithmic units range. 

Table 4: Partitions and shake-flask procedures proposed for log D determination

\begin{tabular}{|c|c|c|c|c|}
\hline log $D$ range & Partitions & Procedure & Equation & Observations \\
\hline $\log D<-1$ & $\begin{array}{l}b, c \\
c, d\end{array}$ & $\begin{array}{l}2 \\
1\end{array}$ & $\begin{array}{l}6 \\
5\end{array}$ & Partition $\boldsymbol{d}$ only for log $\mathrm{D}$ values higher than -1.5 \\
\hline$-1<\log D<0$ & $c, d$ & 1 & 5 & \\
\hline $0<\log D<1.5$ & $c, d, e$ & 1 & 5 & $\begin{array}{l}\text { Partitions } \boldsymbol{d} \text { and } \boldsymbol{e} \text { might be used for higher } \log \mathrm{D} \\
\text { values if a more sensible detector is used. }\end{array}$ \\
\hline $1.5<\log D<3.0$ & $f, g, h$ & 1 & 5 & $\begin{array}{l}\text { For high log } D \text { values the suitability of partition } f \\
\text { depends on the sensitivity of the detector. }\end{array}$ \\
\hline $3.0<\log D<3.5$ & $g, h$ & 1 & 5 & \\
\hline $\log D>3.5$ & $\begin{array}{c}g, h \\
h\end{array}$ & $\begin{array}{c}3 \\
1 b\end{array}$ & $\begin{array}{l}7 \\
5\end{array}$ & $\begin{array}{l}\text { Procedure } 1 \text { could be used if no solubility problems } \\
\text { are detected }\end{array}$ \\
\hline
\end{tabular}


Table 5: $\log D_{7.4}$ for a set of 28 compounds

\begin{tabular}{|c|c|c|c|c|c|c|c|}
\hline \multirow[b]{2}{*}{ Compound } & \multirow[b]{2}{*}{$\begin{array}{c}\log D_{7.4} \\
\text { BioLoom database }{ }^{a}\end{array}$} & \multirow[b]{2}{*}{ Procedure } & \multirow[b]{2}{*}{ Partition } & \multicolumn{2}{|c|}{ HPLC - DAD } & \multicolumn{2}{|c|}{ UPLC - DAD } \\
\hline & & & & $\log D_{7.4}$ & Average & $\log D_{7.4}$ & Average \\
\hline \multirow[t]{3}{*}{ Atenolol } & \multirow{3}{*}{-1.94} & 2 & $b$ & $-1.76 \pm 0.11$ & \multirow{3}{*}{$-1.81 \pm 0.23$} & & \\
\hline & & 2 & $c$ & $-1.93 \pm 0.29$ & & & \\
\hline & & 1 & $c$ & $-1.64 \pm 0.07$ & & & \\
\hline \multirow[t]{3}{*}{ Salicylic acid } & \multirow{3}{*}{$-1.65 \pm 0.59$} & 2 & $b$ & $-1.77 \pm 0.04$ & \multirow{3}{*}{$-1.85 \pm 0.14$} & --- & \multirow{3}{*}{$-1.43 \pm 0.11$} \\
\hline & & 2 & $c$ & $-1.98 \pm 0.12$ & & --- & \\
\hline & & 1 & $c$ & $-1.78 \pm 0.10$ & & $-1.43 \pm 0.11$ & \\
\hline \multirow[t]{4}{*}{ Benzoic acid } & \multirow{4}{*}{-1.43} & 2 & $b$ & $-1.37 \pm 0.19$ & \multirow{4}{*}{$-1.27 \pm 0.15$} & $-1.37 \pm 0.01$ & \multirow{4}{*}{$-1.27 \pm 0.19$} \\
\hline & & 1 & $b$ & --- & & $-1.34 \pm 0.03$ & \\
\hline & & 1 & $c$ & $-1.22 \pm 0.07$ & & $-1.32 \pm 0.18$ & \\
\hline & & 1 & $d$ & $-1.26 \pm 0.20$ & & $-1.01 \pm 0.07$ & \\
\hline \multirow{2}{*}{ Metoprolol } & \multirow{2}{*}{$-0.15 \pm 0.24$} & 1 & $c$ & $-0.20 \pm 0.10$ & \multirow{2}{*}{$-0.28 \pm 0.10$} & $-0.38 \pm 0.02$ & \multirow{2}{*}{$-0.33 \pm 0.06$} \\
\hline & & 1 & $d$ & $-0.35 \pm 0.05$ & & $-0.29 \pm 0.05$ & \\
\hline Caffeine & & 1 & $c$ & $-0.08 \pm 0.01$ & & $-0.04 \pm 0.01$ & \\
\hline & -0.07 & 1 & $d$ & $0.00 \pm 0.15$ & $-0.04 \pm 0.12$ & $-0.03 \pm 0.01$ & $-0.03 \pm 0.01$ \\
\hline & & 1 & $e$ & --- & & $-0.01 \pm 0.02$ & \\
\hline Theophylline & & 1 & $c$ & $-0.12 \pm 0.04$ & Q & $-0.02 \pm 0.01$ & \\
\hline & -0.02 & 1 & $d$ & $0.03 \pm 0.06$ & כ & $0.02 \pm 0.02$ & $-0.01 \pm 0.03$ \\
\hline & & 1 & $e$ & --- & & $-0.03 \pm 0.03$ & \\
\hline Procaine & & 1 & c & $0.26 \pm 0.15$ & & $0.27 \pm 0.06$ & \\
\hline & 0.23 & 1 & $d$ & $0.30 \pm 0.21$ & $0.28 \pm 0.17$ & $0.31 \pm 0.04$ & $0.29 \pm 0.05$ \\
\hline & & 1 & $e$ & --- & & $0.28 \pm 0.01$ & \\
\hline Paracetamol & & 1 & $c$ & $0.25 \pm 0.01$ & & $0.33 \pm 0.01$ & \\
\hline & 0.51 & 1 & $d$ & $0.42 \pm 0.03$ & $0.39 \pm 0.13$ & $0.34 \pm 0.01$ & $0.33 \pm 0.02$ \\
\hline & & 1 & $e$ & $0.53 \pm 0.20$ & & $0.32 \pm 0.02$ & \\
\hline Warfarin & & 1 & c & $0.74 \pm 0.21$ & & $0.96 \pm 0.03$ & \\
\hline & $0.88 \pm 0.28$ & 1 & $d$ & $0.83 \pm 0.21$ & $0.83 \pm 0.19$ & $0.90 \pm 0.04$ & $0.91 \pm 0.05$ \\
\hline & & 1 & $e$ & $0.86 \pm 0.18$ & & $0.88 \pm 0.02$ & \\
\hline Colchicine & & 1 & c & $0.91 \pm 0.01$ & & $1.14 \pm 0.04$ & \\
\hline & 1.30 & 1 & $d$ & $1.16 \pm 0.15$ & $1.09 \pm 0.05$ & $1.14 \pm 0.02$ & $1.15 \pm 0.03$ \\
\hline & & 1 & $e$ & $1.04 \pm 0.01$ & & $1.16 \pm 0.01$ & \\
\hline Acetanilide & & 1 & $c$ & $1.15 \pm 0.01$ & & $1.18 \pm 0.06$ & \\
\hline & 116 & 1 & $d$ & $1.21 \pm 0.01$ & $119+005$ & $1.18 \pm 0.01$ & $119+004$ \\
\hline & 1.10 & 1 & $e$ & $1.20 \pm 0.01$ & 1.1010 .0 & $1.21 \pm 0.02$ & $1.15 \pm 0.04$ \\
\hline & & 1 & $f$ & $1.17 \pm 0.09$ & & --- & \\
\hline Propranolol & & 1 & c & $1.30 \pm 0.04$ & & $1.22 \pm 0.02$ & \\
\hline & $1.24 \pm 0.15$ & 1 & $d$ & $1.24 \pm 0.02$ & $1.23 \pm 0.05$ & $1.22 \pm 0.08$ & $1.22 \pm 0.06$ \\
\hline & & 1 & $e$ & $1.19 \pm 0.01$ & & $1.23 \pm 0.08$ & \\
\hline Lidocaine & & 1 & $d$ & $1.47 \pm 0.33$ & & $1.80 \pm 0.07$ & \\
\hline & & 1 & $e$ & $1.57 \pm 0.13$ & & $1.78 \pm 0.12$ & \\
\hline & $1.53 \pm 0.26$ & 1 & $f$ & $1.92 \pm 0.01$ & $1.61 \pm 0.26$ & $1.71 \pm 0.11$ & $1.70 \pm 0.19$ \\
\hline & & 1 & $g$ & --- & & $1.58 \pm 0.31$ & \\
\hline & & 1 & $\boldsymbol{h}$ & --- & & $1.73 \pm 0.09$ & \\
\hline Acetophenone & & 1 & $d$ & $1.58 \pm 0.13$ & & --- & \\
\hline & 158 & 1 & $e$ & $1.58 \pm 0.30$ & $157+016$ & --- & $155+016$ \\
\hline & 1.50 & 1 & $f$ & $1.54 \pm 0.11$ & $1.51 \pm 0.10$ & $1.52 \pm 0.10$ & 0 \\
\hline & & 1 & $g$ & $1.67 \pm 0.29$ & & $1.55 \pm 0.09$ & \\
\hline
\end{tabular}




\begin{tabular}{|c|c|c|c|c|c|c|c|}
\hline & & 1 & $\boldsymbol{h}$ & $1.52 \pm 0.21$ & & $1.60 \pm 0.12$ & \\
\hline \multirow[t]{3}{*}{ Hydrocortisone } & \multirow{3}{*}{1.61} & 1 & $d$ & $1.54 \pm 0.10$ & \multirow{3}{*}{$1.58 \pm 0.12$} & & \\
\hline & & 1 & $e$ & $1.54 \pm 0.13$ & & & \\
\hline & & 1 & $f$ & $1.67 \pm 0.06$ & & & \\
\hline \multirow[t]{5}{*}{ Propiophenone } & \multirow{5}{*}{2.19} & 1 & $d$ & $2.14 \pm 0.16$ & \multirow{5}{*}{$2.24 \pm 0.16$} & --- & \multirow{5}{*}{$1.98 \pm 0.19$} \\
\hline & & 1 & $e$ & $2.37 \pm 0.17$ & & --- & \\
\hline & & 1 & $f$ & $2.17 \pm 0.12$ & & $2.00 \pm 0.16$ & \\
\hline & & 1 & $g$ & $2.25 \pm 0.13$ & & $1.88 \pm 0.26$ & \\
\hline & & 1 & $h$ & $2.34 \pm 0.09$ & & $2.03 \pm 0.14$ & \\
\hline \multirow[t]{5}{*}{ Butyrophenone } & \multirow{5}{*}{2.66} & 1 & $d$ & $2.37 \pm 0.06$ & \multirow{5}{*}{$2.65 \pm 0.23$} & --- & \multirow{5}{*}{$2.66 \pm 0.10$} \\
\hline & & 1 & $e$ & $2.46 \pm 0.02$ & & --- & \\
\hline & & 1 & $f$ & $2.73 \pm 0.31$ & & $2.64 \pm 0.07$ & \\
\hline & & 1 & $g$ & $2.68 \pm 0.16$ & & $2.59 \pm 0.09$ & \\
\hline & & 1 & $h$ & $2.83 \pm 0.16$ & & $2.73 \pm 0.10$ & \\
\hline \multirow[t]{3}{*}{ Haloperidol } & \multirow{3}{*}{$2.92 \pm 0.34$} & 1 & $f$ & $2.53 \pm 0.06$ & \multirow{3}{*}{$2.77 \pm 0.26$} & $2.78 \pm 0.08$ & \multirow{3}{*}{$2.78 \pm 0.09$} \\
\hline & & 1 & $g$ & $2.94 \pm 0.12$ & & $2.79 \pm 0.10$ & \\
\hline & & 1 & $h$ & $3.08 \pm 0.09$ & & $2.79 \pm 0.09$ & \\
\hline \multirow[t]{3}{*}{ Valerophenone } & \multirow{3}{*}{---} & 1 & $f$ & $3.30 \pm 0.15$ & \multirow{3}{*}{$3.40 \pm 0.14$} & $\begin{array}{ll}-- \\
\end{array}$ & \multirow{3}{*}{$3.22 \pm 0.12$} \\
\hline & & 1 & $g$ & $3.38 \pm 0.17$ & & $3.13 \pm 0.08$ & \\
\hline & & 1 & $h$ & $3.47 \pm 0.07$ & & $3.31 \pm 0.04$ & \\
\hline \multirow[t]{2}{*}{ Napththalene } & \multirow{2}{*}{3.3} & 1 & $g$ & $3.05 \pm 0.08$ & \multirow{2}{*}{$3.19 \pm 0.14$} & $2.89 \pm 0.01$ & \multirow{2}{*}{$3.21 \pm 0.25$} \\
\hline & & 1 & $h$ & $3.28 \pm 0.02$ & & $3.37 \pm 0.10$ & \\
\hline Thymol & 32 & 1 & $g$ & $3.43 \pm 0.27$ & & $3.34 \pm 0.06$ & \\
\hline & 3.3 & 1 & $h$ & $3.29 \pm 0.19$ & $3.34 \pm 0.23$ & $3.31 \pm 0.04$ & $3.32 \pm 0.05$ \\
\hline Ketoconazole & & 1 & $g$ & $3.50 \pm 0.16$ & & $3.39 \pm 0.18$ & \\
\hline & 3.83 & 1 & $h$ & $3.32 \pm 0.21$ & $3.42 \pm 0.20$ & $3.28 \pm 0.01$ & $3.36 \pm 0.15$ \\
\hline Reserpine & & 3 & $f$ & $3.67 \pm 0.08$ & & --- & \\
\hline & 3.72 & 3 & $g$ & $4.02 \pm 0.11$ & $3.89 \pm 0.21$ & $4.44 \pm 0.05$ & $4.27 \pm 0.18$ \\
\hline & & 3 & $h$ & $3.98 \pm 0.21$ & & $4.11 \pm 0.03$ & \\
\hline \begin{tabular}{|l|} 
Hexanophenone \\
\end{tabular} & & 3 & $g$ & $3.72 \pm 0.26$ & & $3.86 \pm 0.02$ & \\
\hline & & 3 & $h$ & $3.67 \pm 0.21$ & & $4.54 \pm 0.03$ & \\
\hline & --- & $1 b$ & $g$ & & $3.69 \pm 0.23$ & $3.71 \pm 0.01$ & $4.05 \pm 0.32$ \\
\hline & & $1 b$ & $h$ & & & $4.07 \pm 0.02$ & \\
\hline Phenothiazine & & 3 & $g$ & $4.21 \pm 0.18$ & & $3.87 \pm 0.02$ & \\
\hline & 4.15 & 3 & $h$ & $4.01 \pm 0.24$ & $4.11 \pm 0.22$ & $4.02 \pm 0.02$ & $4.02 \pm 0.04$ \\
\hline & & $1 b$ & $h$ & & & & \\
\hline Heptanophenone & & 3 & $g$ & $4.42 \pm 0.21$ & & $4.33 \pm 0.02$ & \\
\hline & --- & 3 & $h$ & $4.41 \pm 0.38$ & $4.41 \pm 0.27$ & $4.65 \pm 0.04$ & $4.52 \pm 0.16$ \\
\hline & & $1 b$ & $h$ & & & $4.59 \pm 0.13$ & \\
\hline Anthracene & & 3 & $g$ & $4.52 \pm 0.21$ & & $4.65 \pm 0.02$ & \\
\hline & 4.45 & 3 & $h$ & $4.47 \pm 0.24$ & $4.49 \pm 0.23$ & --- & $4.37 \pm 0.23$ \\
\hline & & $1 b$ & $h$ & & & $4.24 \pm 0.15$ & \\
\hline Phenanthrene & 117 & 3 & $g$ & $4.62 \pm 0.11$ & $4.58 \pm 0.09$ & & \\
\hline & 4.47 & 3 & $h$ & $4.55 \pm 0.07$ & & & \\
\hline
\end{tabular}

afrom reference (Biobyte Corp.1995-2006, n.d.). Values without standard deviation correspond to the recommended ones, whereas the ones with standard deviation correspond an average of the collected values. 